\title{
Cyclic Oligolactic Acid in Direct Polycondensation PLLA and Its Extraction with Organic Solvent
}

\author{
Keiichiro Nomura, ${ }^{1}$ Yuta Nakatsuchi, ${ }^{1}$ Ryugo Shinmura, ${ }^{1}$ Sommai Pivsa-Art, ${ }^{2}$ \\ Weraporn Pivsa-Art, ${ }^{1,2}$ Yuji Aso, ${ }^{1}$ and Hitomi Ohara ${ }^{1}$ \\ ${ }^{1}$ Department of Biobased Materials Science, Kyoto Institute of Technology, Matsugasaki, Sakyo-ku, Kyoto 606-8585, Japan \\ ${ }^{2}$ Rajamangala University of Technology Thanyaburi, Rangsit-Nakhon Nayok, Pathum Thani 12110, Thailand \\ Correspondence should be addressed to Hitomi Ohara; ohara@kit.ac.jp
}

Received 22 August 2014; Revised 17 October 2014; Accepted 18 October 2014; Published 25 November 2014

Academic Editor: Iliya Rashkov

Copyright ( 2014 Keiichiro Nomura et al. This is an open access article distributed under the Creative Commons Attribution License, which permits unrestricted use, distribution, and reproduction in any medium, provided the original work is properly cited.

\begin{abstract}
The contents of poly(L-lactic acid) (PLLA) prepared by direct condensation polymerization without using a catalyst were studied. ${ }^{1} \mathrm{H}$ NMR and mass spectrometry analyses suggested that PLLA contained cyclic oligo(L-lactic acid) (c-OLLA) with 3-20 repeat units. Notably, only c-OLLA was extracted and isolated using hexane or cyclohexane at $4^{\circ} \mathrm{C}$; thus the hydrophobicity, topology, and temperature dependence of the solubility of the obtained PLLA enabled the selective extraction of c-OLLA. The effect of cyclic compounds on direct polycondensation and the potential for c-OLLA to form molecular inclusion complexes were also discussed.
\end{abstract}

\section{Introduction}

Poly(L-lactic acid) (PLLA) has attracted attention for its carbon neutrality and biodegradability. Various grades of PLLA, including some with molecular weights greater than one hundred thousand, are now industrially produced. Generally, these polymers are regarded as linear molecules and are synthesized by the ring-opening polymerization of L,L-lactide [1] or the direct condensation polymerization of L-lactic acid with catalyst [2]. On the other hand, methods for the synthesis of cyclic poly(L-lactic acid) (c-PLLA) have been reported recently. For example, c-PLLA with molecular weights of approximately 4,000-39,000 (the number of repeat units; 60540) was synthesized using an alumatrane-inspired catalyst [3]. Shin et al. also prepared c-PLLA by the zwitterionic polymerization of lactide using the $\mathrm{N}$-heterocyclic carbene 1,3-dimesitylimidazol-2-ylidene (IMes) as the catalyst and investigated the crystallinity of the polymer [4].

Cyclic esters, also known as lactones, are found in living systems. For example, 3-methyl-4-octanolide is present in oak trees [5], while exaltolide with a 16-membered ring is known as a musk perfume compound [6].

In the field of medicine, cyclic oligoesters with 14-16 repeat units are generally known as macrolides, which exhibit antibacterial activity [7-9]. In addition, cyclic oligo(L-lactic acid) (c-OLLA), which is composed of lactic acid, is recognized as an antitumor material, and studies to elucidate the antitumor activity of c-OLLA have been conducted [10, 11]. OLLA that includes both linear and cyclic compounds suppresses the growth of cancer cells in vivo by directly affecting the glycolytic system. However, it is not clear whether it is the linear or cyclic compounds that affect the cancer cells, because there is no description for the preparation of OLLA which does not include linear OLLA (1-OLLA). Therefore, in order to elucidate the function of the cyclic compounds, the isolation of pure c-OLLA is necessary.

Cyclic compounds are assumed to be contained in the products obtained from the direct polycondensation of lactic acid; we attempted to isolate cyclic compounds simpler way and study the interaction behavior of cyclic compounds contained in PLLA prepared by direct melt polycondensation.

\section{Experiment}

2.1. Materials. L-lactic acid (90 wt\% aq. solution, HiPure 90, Purac Biochem. bv., NL) was used without purification. Special grade chloroform, methanol, diethyl ether, hexane, 
and cyclohexane (Sigma-Aldrich Inc., USA) solvents were also used without purification.

2.2. Polycondensation of $\mathrm{L}$-Lactic Acid. PLLA was synthesized by the direct condensation polymerization method reported in [12], except that no catalyst was added. A $300 \mathrm{~mL}$ threeneck separable flask was equipped with a magnetic stirrer and reflux condenser, which was connected to a vacuum system through a cold trap. First, L-lactic acid (100 g) was charged into the flask and heated to $160^{\circ} \mathrm{C}$ in stages with stirring while the pressure was reduced stepwise to $4 \mathrm{kPa}$, at which point, the reaction was continued for $21 \mathrm{~h}$. As the reaction proceeded, the solution gradually became viscous. When the reaction was complete, the flask was cooled to room temperature $\left(26^{\circ} \mathrm{C}\right)$, and the product was crushed into a powder using a mortar.

2.3. Extraction of c-OLLA. Powdered PLLA $(5 \mathrm{~g})$ was added to a solvent $(50 \mathrm{~mL})$, including methanol, diethyl ether, hexane, and cyclohexane, at room temperature or $4^{\circ} \mathrm{C}$ (ice water bath).

PLLA was not completely dissolved in any of the solvents. Insoluble materials were removed from the mixture by filtration. The filtrates were then analyzed by electrospray ionization mass spectrometry (ESI-MS), nuclear magnetic resonance (NMR) spectroscopy, and matrix-assisted laser desorption/ionization mass spectrometry (MALDI-MS) after solvent removal under vacuum at $40^{\circ} \mathrm{C}$.

2.4. Analysis. Each sample was dissolved in 1,1,1,3,3,3-hexafluoro-2-propanol (HFIP) containing $10 \mathrm{mM}$ trifluoroacetic acid $(0.68 \mathrm{~g} / \mathrm{L})$ in order to determine its weight-average molecular weight $\left(M_{w}\right)$ and number-average molecular weight $\left(M_{n}\right)$ by gel permeation chromatography (GPC, e2695, Waters Co., USA) using a refractive index (RI) detector. A column for organic solvents (Shodex HFIP-806 M, Showa Denko k.k., Japan) was used with the guard column. The operating conditions were as follows: column temperature, $30^{\circ} \mathrm{C}$; flow rate, $1 \mathrm{~mL} / \mathrm{min}$; and calibration, polystyrene.

The optical purity of the lactic acid units was determined by high performance liquid chromatography (HPLC, LC-20 series, Shimadzu Co., Japan) of the lactic acid formed after the acid hydrolysis of the polymer samples. A Mitsubishi Chemical MCI GELCRS10W column was used for isolation of the optical isomers. Before the analysis, a $1.5 \mathrm{mg}$ of polymer sample was dipped in $0.5 \mathrm{~mL}$ of $2 \mathrm{M} \mathrm{NaOH}$ for hydrolysis at room temperature. The resultant solution was then neutralized with $1 \mathrm{M} \mathrm{H}_{2} \mathrm{SO}_{4}(0.5 \mathrm{~mL})$, diluted by $10 \%$, and injected to the analyzer. The analytical conditions are as follows: column temperature, $35^{\circ} \mathrm{C}$; solvent for elution, $1 \mathrm{mM} \mathrm{CuSO}_{4}$ aqueous solution; and flow rate, $0.5 \mathrm{~mL} / \mathrm{min}$. Both L-and Dlactic acids were detected by a UV detector at wavelength $254 \mathrm{~nm}$. Optical purity was evaluated by the following \%ee:

$$
\% \text { ee }=100 \times \frac{([\mathrm{L}]-[\mathrm{D}])}{([\mathrm{L}]+[\mathrm{D}])},
$$

where $[\mathrm{L}]$ and $[\mathrm{D}]$ denote the molarities of $\mathrm{L}^{-}$and $\mathrm{D}$-lactic acids, respectively.
ESI-MS spectra were recorded using an ion trap mass spectrometer (amaZon SL, Bruker Daltonics Inc., USA). The operating conditions were as follows: flow rate, $240 \mu \mathrm{L} / \mathrm{h}$; capillary temperature, $175^{\circ} \mathrm{C}$; spray voltage, $4.5 \mathrm{kV}$; and capillary voltage, $40 \mathrm{~V}$. Samples were dissolved in liquid chromatography/mass spectrometry- (LC/MS-) grade acetonitrile (Kanto Chemical Co., Inc., Japan).

${ }^{1} \mathrm{H}$ NMR spectra were recorded using an AVANCE Series $300 \mathrm{MHz}$ spectrometer (Bruker Biospin Co., USA) operating at $300 \mathrm{MHz}$. Samples were dissolved in DMSO- $d_{6}$ (SigmaAldrich Inc.) containing $0.03 \mathrm{vol} \%$ tetramethylsilane as the internal reference. The sample concentration was $100 \mathrm{mg} / \mathrm{mL}$, and the spectra were recorded at $23^{\circ} \mathrm{C}$.

Melting and glass transition temperatures $\left(T_{m}\right.$ and $T_{q}$, resp.) were determined by differential scanning calorimetry (DSC, Q200, TA Instruments, USA). Samples were heated at a rate of $5^{\circ} \mathrm{C} / \mathrm{min}$ under a flow of nitrogen gas.

MALDI-MS spectra were recorded using an autoflex speed-KF system (Bruker Daltonics Inc.) equipped with a nitrogen laser (Smartbeam-II, $355 \mathrm{~nm}$ ). The acceleration voltage was $19 \mathrm{kV}$, and the spectra were obtained in the linear, positive ion mode with pulsed ion extraction (120 ns). The energy of the laser beam was set at approximately $70 \%$, and the spectra were acquired in $\mathrm{m} / \mathrm{z}$ range from 500 to 10,000 . External calibration was performed using appropriate samples of Angiotensin II. The samples were measured by employing in a solvent-free MALDI-MS method in trans-3-indoleacrylic acid matrix in the presence of $\mathrm{NaI}$ as cationization agent.

\section{Results and Discussion}

The $M_{n}$ and $M_{w}$ of polymerized PLLA were 7,500 and 9,200, respectively. The optical purity of the PLLA was $96.0 \%$ ee while that of L-lactic acid was $99.9 \%$ ee. Figure 1(a) shows the ${ }^{1} \mathrm{H}$ NMR spectrum of PLLA. The signals were assigned on the basis of data reported in [13]. The signals were assigned as in Figure 1. The protons relatively close to end groups, assigned as signals $\left(a_{2}\right),\left(a_{3}\right)$, and $\left(a_{4}\right)$, tend to be affected by carboxyl end group or hydroxyl end group. Notably, the signal attributed to the proton closest to the carboxyl end group $\left(a_{2}\right)$ in Figure 1(a) was detected in the spectrum of PLLA, indicating that it contained linear oligo(L-lactic acid). In addition, the ${ }^{1} \mathrm{H}$ NMR spectra of the products extracted with methanol at room temperature and hexane at $4^{\circ} \mathrm{C}$ are also shown in Figures 1(b) and 1(c). For the product extracted with methanol, the signal attributed to the proton closest to the carboxyl end group was also observed, indicating that 1-OLLA was extracted. This signal was also detected when methanol at $4^{\circ} \mathrm{C}$ or diethyl ether was used as the extraction solvent (data not shown). In contrast, no signal attributed to the proton closest to the carboxyl end group was observed in the ${ }^{1} \mathrm{H}$ NMR spectra of the products obtained after extraction with cold hexane or cyclohexane. Rather, the signal due to the proton farthest away from the end group $\left(a_{1}\right)$ in Figure 1(c) was detected; therefore, negligible amount of linear oligomer (1-OLLA) was present in these extracted products.

Figure 2 shows the ESI-MS spectra of the products extracted using each solvent. Notably, peaks for 1-OLLA and 

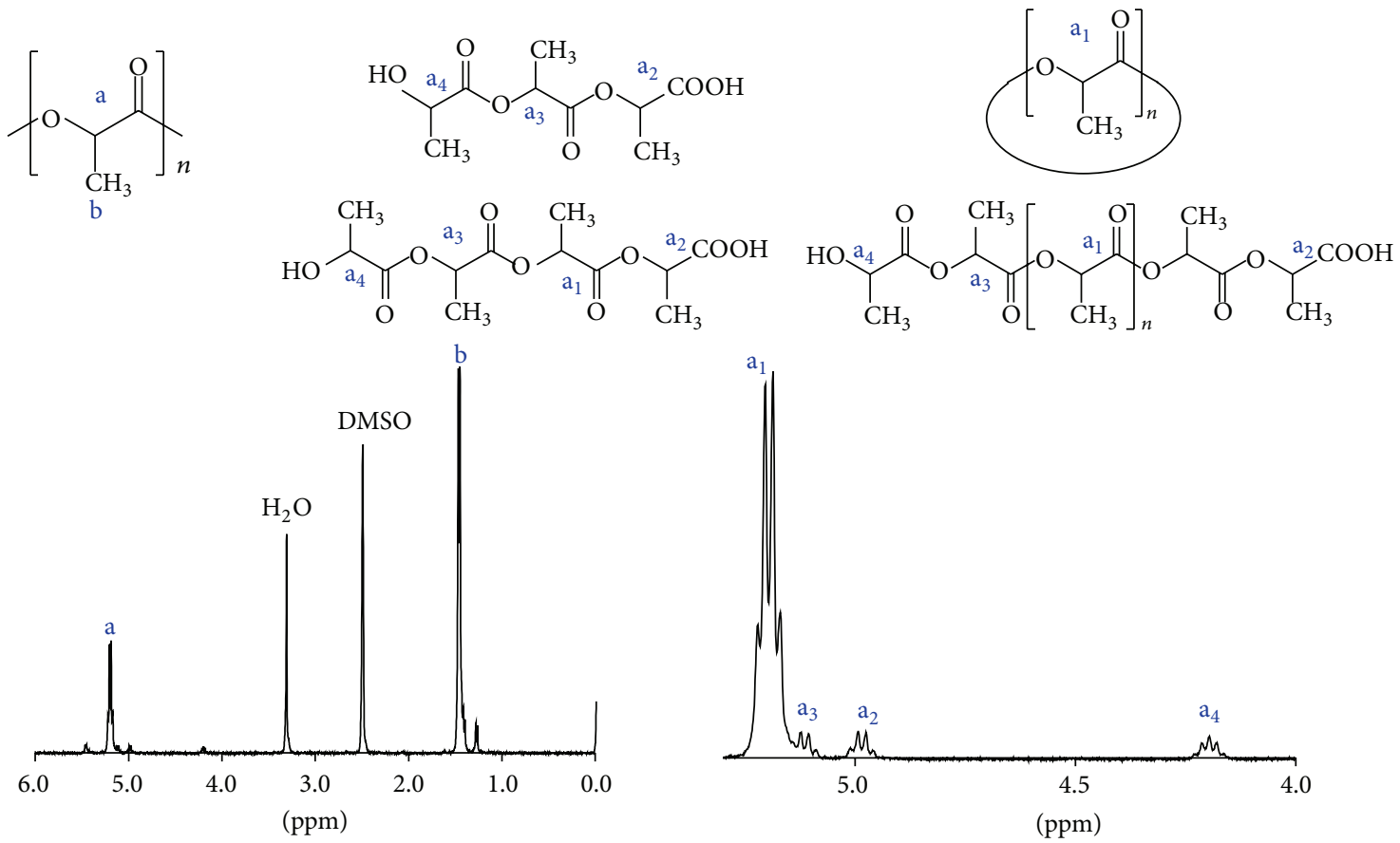

(a)
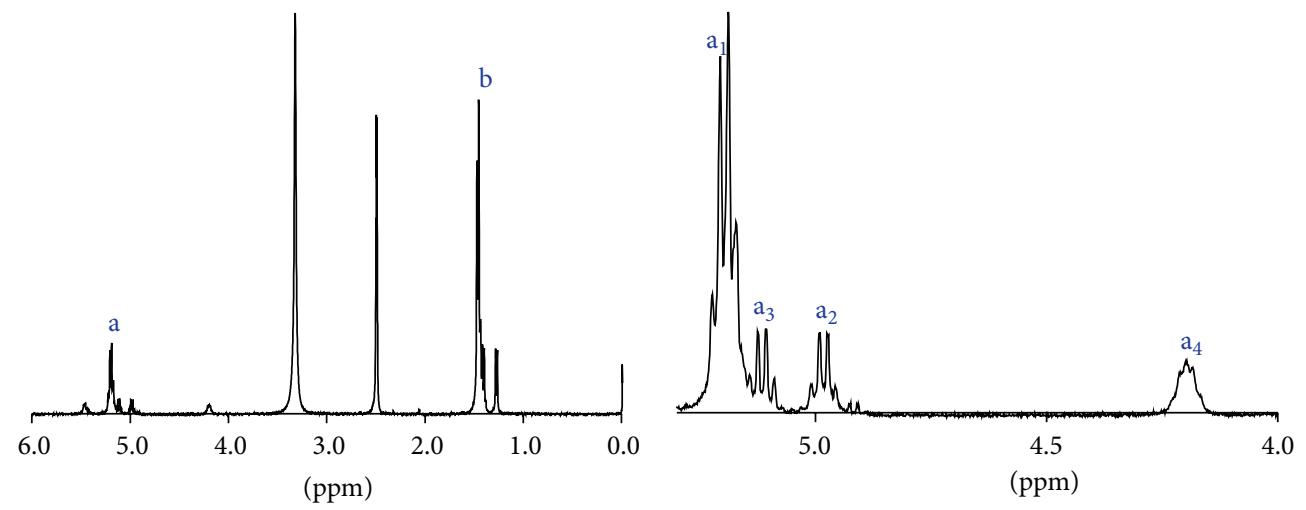

(b)
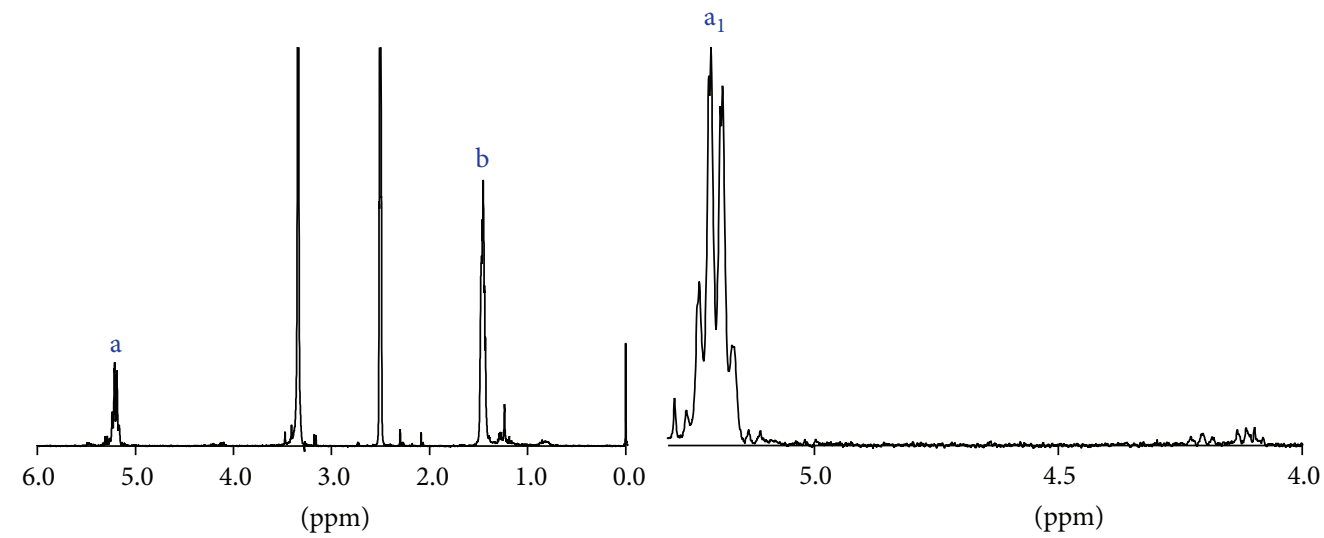

(c)

Figure 1: ${ }^{1} \mathrm{H}$ NMR spectra of (a) PLLA and (b) products extracted with methanol (r.t.) and (c) hexane $\left(4^{\circ} \mathrm{C}\right)$. 


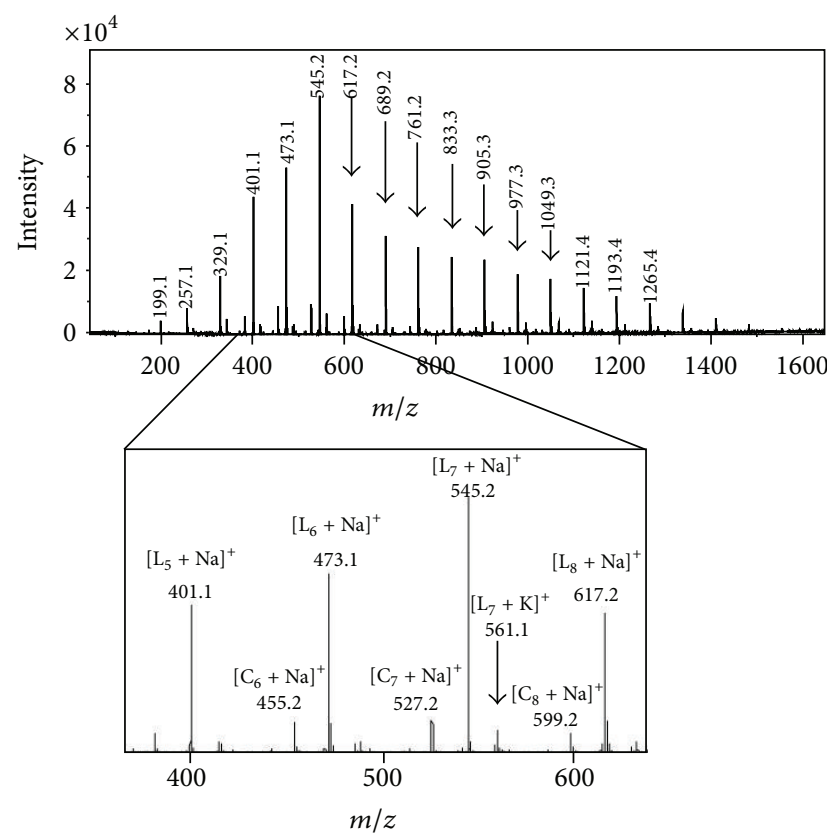

(a)

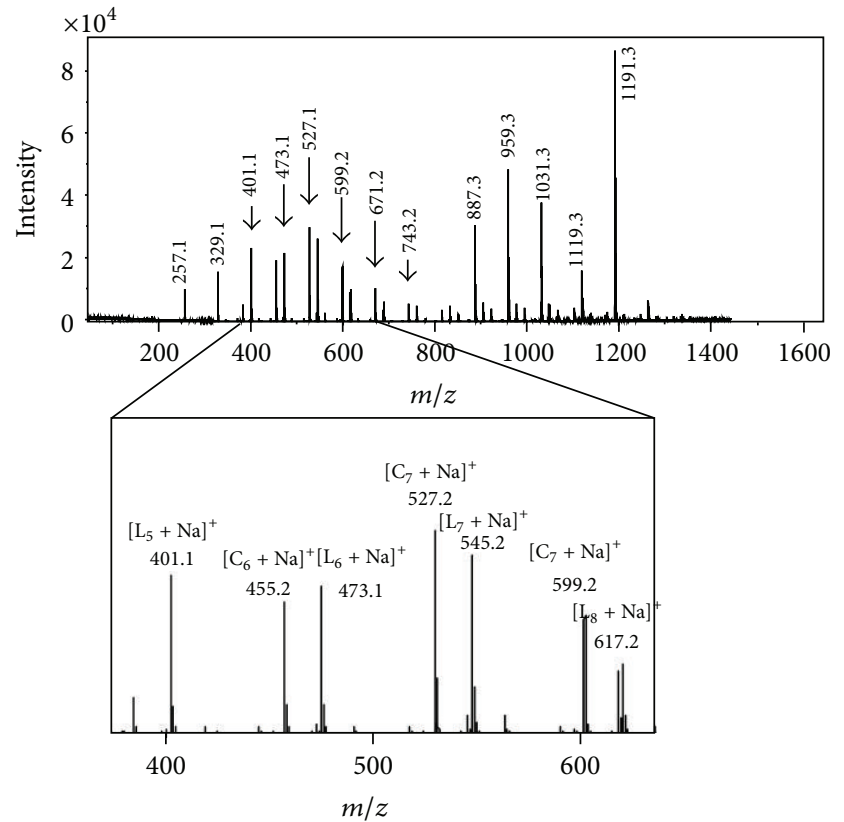

(b)

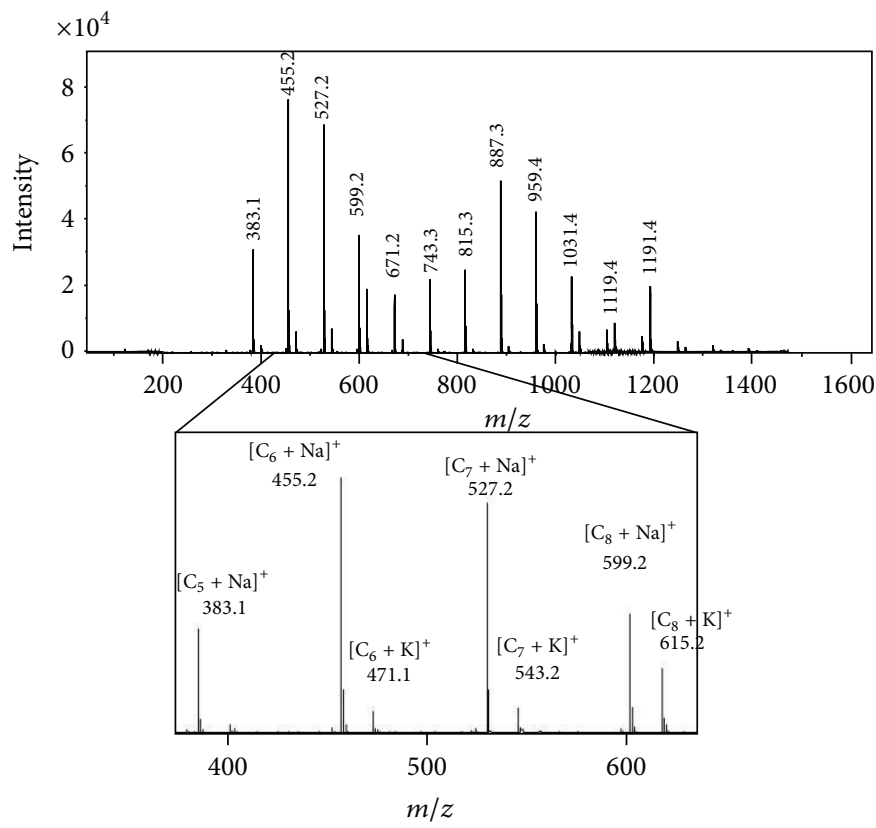

(c)

Figure 2: ESI-MS spectra of products extracted with (a) methanol (r.t.), (b) hexane (r.t.), and (c) hexane $\left(4^{\circ} \mathrm{C}\right) .\left[\mathrm{L}_{5}+\mathrm{Na}^{+}\right.$is due to the $\mathrm{Na}{ }^{+}$ adduct of l-OLLA with $n=5$, and $\left[\mathrm{C}_{8}+\mathrm{K}\right]^{+}$is due to the $\mathrm{K}^{+}$adduct of c-OLLA with $n=8$.

c-OLLA adducted with $\mathrm{Na}^{+}$and $\mathrm{K}^{+}$were detected. The products extracted with methanol and diethyl ether at room temperature contained both 1-OLLA and c-OLLA. It can be seen from the MS spectrum of the product extracted with methanol (Figure 2(a)) that OLLA with 3-20 repeat units was obtained. The yield of the methanol-extracted product was $6.79 \mathrm{wt} \%$. While the product extracted with hexane at room temperature also contained both 1-OLLA and c-OLLA (Figure 2(b)), the quantity of c-OLLA was much higher than that for the products extracted with methanol or diethyl ether. Furthermore, the product extracted with cold hexane at $4^{\circ} \mathrm{C}$ contained only c-OLLA, and no l-OLLA was detected (Figure 2(c)). Similar results were obtained when cyclohexane was used as the extraction solvent. The yield of the hexane-extracted product was $0.047 \mathrm{wt} \%$, and the number of repeat units was 5-16.

The evaluation of the ESI-MS results for the product extracted with hexane at $4^{\circ} \mathrm{C}$ also indicated that there was 


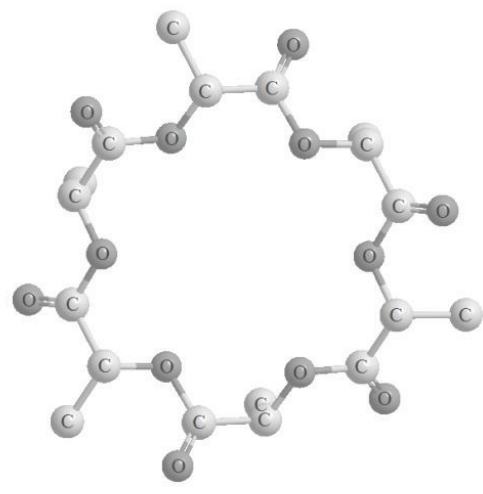

(a)

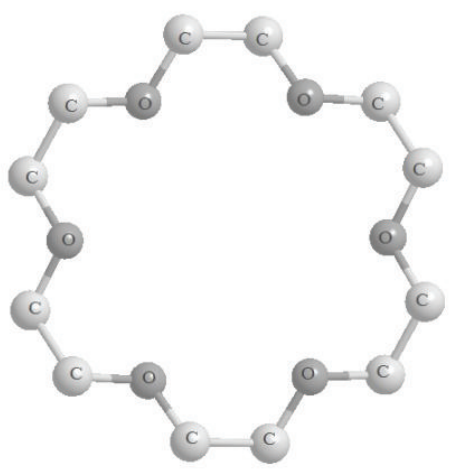

(b)

FIGURE 3: Ball-and-stick model of (a) c-OLLA $(n=6)$ and (b) crown ether (18-crown-6).

appreciable interaction between c-OLLA and alkali metal ions in the acetonitrile solution because c-OLLA has no end group for binding to alkali metal ions. Though it cannot be a direct support of specific binding, it is assumed that the cavity of c-OLLA attracted and included the alkali metal ions.

Generally, cyclic compounds play a significant role in molecular recognition chemistry due to their structural characteristics. It is well known that some cyclic compounds such as crown ethers and cyclodextrins serve as host molecules, forming molecular inclusion complexes with specific guest molecules [14]. Crown ethers have been widely studied for many years and are used in many fields [15-18].

It is possible that the c-OLLA formed inclusion complexes with $\mathrm{Na}^{+}$and $\mathrm{K}^{+}$in a manner similar to crown ethers. Figure 3 shows the chemical structure of c-OLLA $(n=6)$ and crown ether. It should also be noted that c-OLLA may be a novel host molecule, unlike crown ethers, which was produced from biocompatible and biodegradable polymer that can be used in human body.

Next, PLLA and extracted products were evaluated by DSC, and the results of 1st heating are presented in Figure 4. It can be seen in the figure that a melting peak was detected for both PLLA and the product extracted using cold methanol, while only a glass transition point was observed for the product extracted using cold hexane. This result indicates that PLLA and the product extracted with cold methanol which contains l-OLLA mainly have crystallinity, while the product extracted with cold hexane, more specifically, c-OLLA is amorphous. The glass transition temperatures $\left(T_{g}\right)$ for PLLA and l-OLLA and C-OLLA were $52^{\circ} \mathrm{C}, 40^{\circ} \mathrm{C}$, and $22^{\circ} \mathrm{C}$, respectively. This fact indicates that molecular chain in c-OLLA was easy to move even though below $T_{g}$ and it made it easy to be extracted with poor solvent like hexane as shown in Figure 2(c). In contrast, l-OLLA was also easy to move at room temperature $\left(26^{\circ} \mathrm{C}\right)$, so that not only c-OLLA but also 1-OLLA was extracted by hexane. The liquid-state linear and cyclic oligomers readily dissolved in various solvents near or above the $T_{g}$ of PLLA, while the liquid state oligomer transformed to a solid (or glassy) state below the $T_{g}$, and as a result, its solubility decreased drastically.

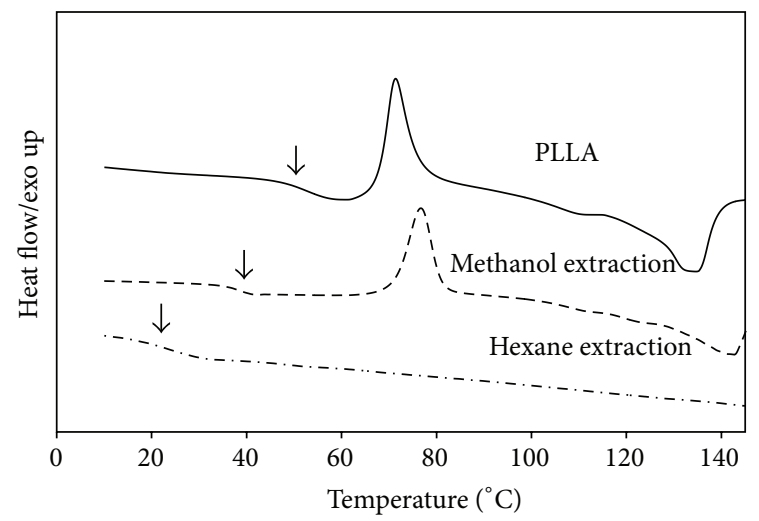

FIgURE 4: DSC results for PLLA and the products extracted with methanol and hexane at $4^{\circ} \mathrm{C} . T_{g}$ values are indicated by arrows.

Furthermore, the solubility parameters (SPs) for hexane and cyclic oligo(L-lactic acid) were calculated by the van Krevelen method [19] and found to be $14.8 \mathrm{MPa}^{0.5}$ and 19.2 $\mathrm{MPa}^{0.5}$, respectively, regardless of the number of repeat units. The SP of 1-OLLA, on the other hand, is dependent on the number of repeat units; for example, the SPs of 1-OLLA trimer and octamer are $22.6 \mathrm{MPa}^{0.5}$ and $20.5 \mathrm{MPa}^{0.5}$, respectively. In general, the difference in the SPs for hexane and cOLLA is small, and therefore, the differences in the polarity of the solvents and topology of the oligomers likely influence the solubility of c-OLLA only at low temperatures. As a result, hexane and cyclohexane were only able to dissolve c-OLLA in a cold environment. Therefore, the differences in the polarity of the solvents likely influence the solubility of c-OLLA only at low temperatures. As a result, hexane and cyclohexane were only able to dissolve c-OLLA in a cold environment. In addition, the difference in the topology of the linear and cyclic molecules affects their solubility, because it is more difficult for cyclic molecules to aggregate.

It should be noted here that there are other methods for obtaining cyclic compounds, such as the removal of linear esters by conversion to their corresponding sodium salts 

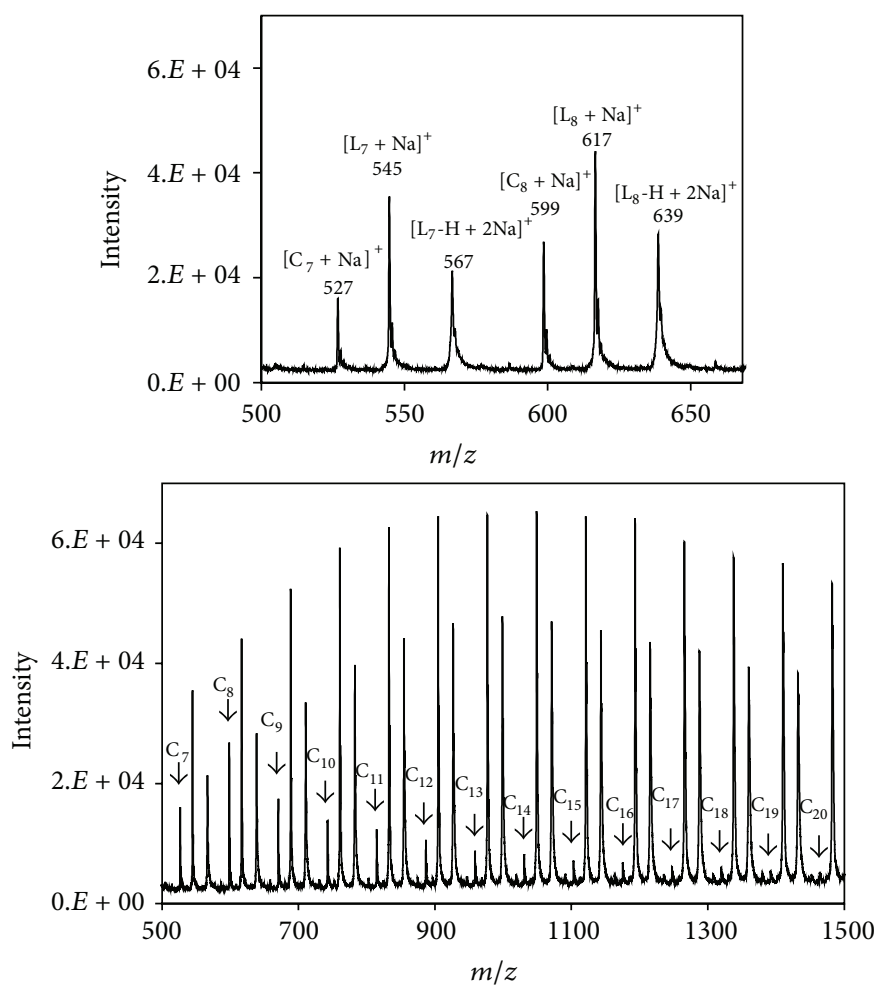

(a1)

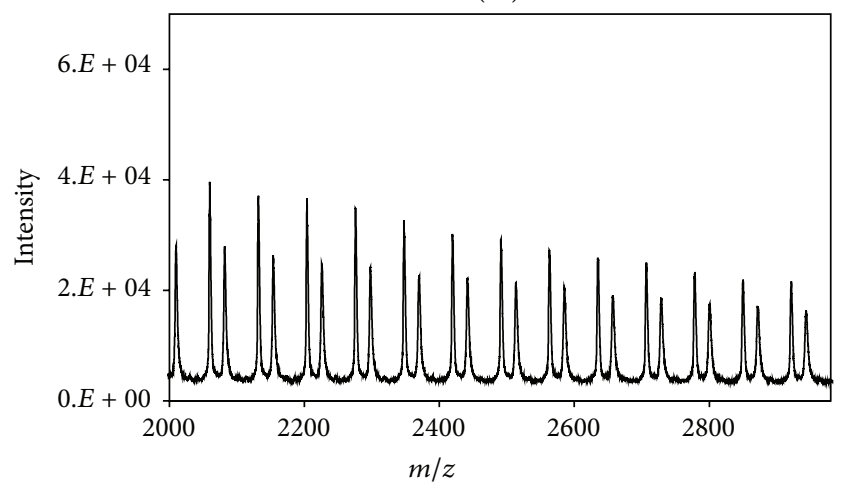

(a)

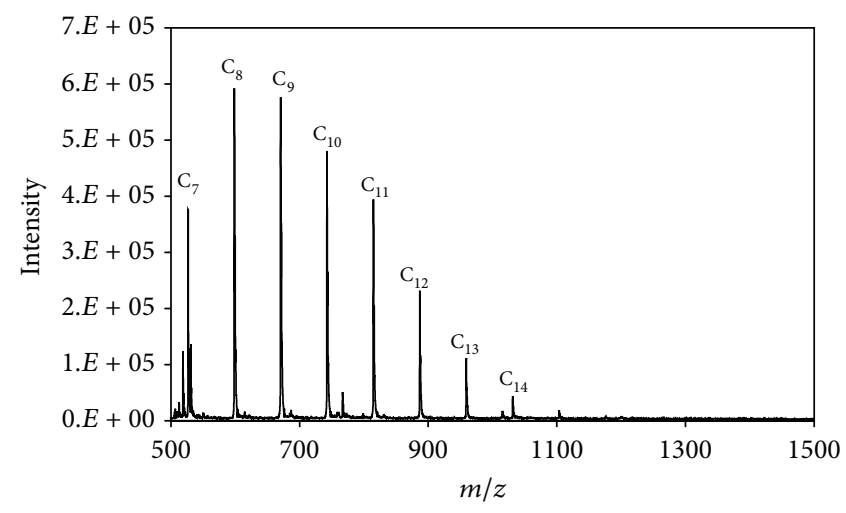

(b)

FIGURE 5: MALDI spectra of (a1) low-molecular-weight range of PLLA (enlarged view below), (a2) high-molecular-weight range of PLLA, and (b) the product extracted with hexane $\left(4^{\circ} \mathrm{C}\right) .\left[\mathrm{L}_{7}+\mathrm{Na}\right]^{+}$is due to the $\mathrm{Na}^{+}$adduct of l-OLLA with $n=7,\left[\mathrm{C}_{7}+\mathrm{K}^{+}\right.$is due to the $\mathrm{K}^{+}$adduct of c-OLLA with $n=7$, and $\left[\mathrm{L}_{7}-\mathrm{H}+2 \mathrm{Na}\right]^{+}$is due to the $2 \mathrm{Na}^{+}$adduct without proton $\mathrm{H}^{+}$of l-OLLA with $n=7$.

[20]. While such an approach is an effective technique for obtaining cyclic compounds and requires rather complicated operation, solvent extraction as demonstrated in this study is a simpler method for extracting c-OLLA, and residues could be hydrolyzed into low-molecular linear compounds. Then the c-OLLA could be produced again for higher yield.

The MALDI-MS spectra of PLLA and the product extracted using cold hexane were obtained to confirm the mass of each molecular and are shown in Figure 5. Peaks for $\mathrm{Na}^{+}$adducted ions of both linear and cyclic products, $[\mathrm{M}+\mathrm{Na}]^{+}$and $[\mathrm{M}-\mathrm{H}+2 \mathrm{Na}]^{+}$, which are often detected in MS measurement [21], were observed in the low-molecularweight range $(m / z=500-1,500)$ in the spectrum of PLLA
(Figure 5(a1)). The cyclic products are indicated by the arrows in the figure. On the other hand, no cyclic products were detected in the high-molecular-weight range $(\mathrm{m} / z>2,000)$ in the spectra of the PLLA (Figure 5(a2)). And products extracted from hexane at $4^{\circ} \mathrm{C}$ did not contain linear products. These results indicate that no high-molecular-weight c-OLLA was produced in the direct melt condensation of lactic acid to form PLLA. It is thought that the concentration of PLLA terminating groups drastically decreases as high-molecularweight linear products are generated during polymerization. As a result, the probability of the terminating groups colliding also decreases, and intramolecular esterification barely proceeds. Meanwhile, the low-molecular-weight linear 
molecules can readily cyclize. Furthermore, it is difficult to increase the molecular weight through the transesterification of the cyclized oligomers if no catalyst is present. This assumption was confirmed by the fact that an L-lactide that forms cyclic products analogous to the cyclic oligomers did not polymerize when heated at $180^{\circ} \mathrm{C}$ without the addition of a catalyst. That is, the c-OLLA may affect direct polycondensation and disturb molecular elongation of PLLA.

\section{Conclusion}

It was confirmed that cyclic products are formed via the direct polycondensation of L-lactic acid to produce PLLA. In addition, the selective extraction of c-OLLA was successfully achieved using cold hexane or cyclohexane as the extraction solvents.

The selective solubility in hexane and cyclohexane at $4^{\circ} \mathrm{C}$ was confirmed by ESI-MS and ${ }^{1} \mathrm{H}-\mathrm{NMR}$ analyses. The results indicated that differences in the hydrophobicity (polar character), topology, and temperature dependence of the solubility of the obtained PLLA enabled the selective extraction of c-OLLA.

The evaluation of the ESI-MS indicated that there was appreciable interaction between c-OLLA and alkali metal ions in the acetonitrile solution because c-OLLA has no end group for binding to alkali metal ions. And it is assumed that the cavity of c-OLLA attracted and included the alkali metal ions. The c-OLLA may be a novel host molecule with biocompatibility and biodegradability which can be used in human body. And it is assumed that the c-OLLA affected the direct polycondensation and disturbed molecular elongation of PLLA.

\section{Conflict of Interests}

The authors declare that there is no conflict of interests regarding the publication of this paper.

\section{References}

[1] J. W. Leenslag and A. J. Pennings, "Synthesis of high-molecularweight poly(L-lactide) initiated with tin 2-ethylhexanoate," Die Makromolekulare Chemie, vol. 188, no. 8, pp. 1809-1814, 1987.

[2] S. I. Moon, C. W. Lee, M. Miyamoto, Y. Kimura, and J. Polym, "Melt polycondensation of L-lactic acid with $\mathrm{Sn}$ (II) catalysts activated by various proton acids: a direct manufacturing route to high molecular weight Poly(L-lactic acid)," Journal of Polymer Science Part A: Polymer Chemistry, vol. 38, no. 9, pp. 1673-1679, 2000.

[3] J. Weil, R. T. Mathers, and Y. D. Y. L. Getzler, "Lactide cyclopolymerization by an alumatrane-inspired catalyst," Macromolecules, vol. 45, no. 2, pp. 1118-1121, 2012.

[4] E. J. Shin, A. E. Jones, and R. M. Waymouth, "Stereocomplexation in cyclic and linear polylactide blends," Macromolecules, vol. 45, no. 1, pp. 595-598, 2012.

[5] M. Masuda and K. Nishimura, "Absolute configurations of quercus lactones, $(3 \mathrm{~s}, 4 \mathrm{r})$ - and $(3 \mathrm{~s}, 4 \mathrm{~s})-3$-methyl-4-octanolide, from oak wood and chiroptical properties of mono-cyclic $\gamma$-lactones," Chemistry Letters, vol. 10, pp. 1333-1336, 1981.
[6] A. Fürstner and K. Langemann, "Macrocycles by ring-closing metathesis," Synthesis, no. 7, pp. 792-803, 1997.

[7] J. Bolard, "How do the polyene macrolide antibiotics affect the cellular membrane properties?" Biochimica et Biophysica Acta, vol. 864, no. 3-4, pp. 257-304, 1986.

[8] J. M. Hamilton-Miller, "Chemistry and biology of the polyene macrolide antibiotics," Bacteriological Reviews, vol. 37, no. 2, pp. 166-196, 1973.

[9] J. Retsema, A. Girard, W. Schelkly et al., "Spectrum and mode of action of azithromycin (CP-62,993), a new 15-memberedring macrolide with improved potency against gram-negative organisms," Antimicrobial Agents and Chemotherapy, vol. 31, no. 12, pp. 1939-1947, 1987.

[10] S. Takada, Y. Nagato, and M. Yamamura, "Effect of cyclic polylactates on tumor cells and tumor bearing mice," Biochemistry and Molecular Biology International, vol. 43, no. 1, pp. 9-17, 1997.

[11] S. Aizawa, N. Shimizu, H. Handa et al., "Effects of cyclic polylactate (CPL) on the growth of cloned leukemic cells in vitro," Hematological Oncology, vol. 18, no. 2, pp. 51-60, 2000.

[12] S. Sawa, T. Kawamoto, Y. Horibe, and H. Ohara, Japan patent JPA1995-138253, 1995.

[13] J. L. Espartero, I. Rashkov, S. M. Li, N. Manolova, and M. Vert, "NMR analysis of low molecular weight poly(lactic acid)s," Macromolecules, vol. 29, no. 10, pp. 3535-3539, 1996.

[14] M. M. Conn and J. Rebek Jr., "Self-assembling capsules," Chemical Reviews, vol. 97, no. 5, pp. 1647-1668, 1997.

[15] C. J. Pedersen, "The discovery of crown Ethers (Noble Lecture)," Angewandte Chemie International Edition, vol. 27, no. 8, pp. 1021-1027, 1988.

[16] C. Seel and F. Vögtle, "Molecules with large cavities in supramolecular chemistry," Angewandte Chemie_International Edition, vol. 31, no. 5, pp. 528-549, 1992.

[17] S. Dai, Y. H. Ju, and C. E. Barnes, "Solvent extraction of strontium nitrate by a crown ether using room-temperature ionic liquids," Journal of the Chemical Society, Dalton Transactions, no. 8, pp. 1201-1202, 1999.

[18] S. Shirakawa, L. Wang, A. Kasai, and K. Maruoka, "New neutral reaction system with crown ether- $\mathrm{KCl}$ complexes in aqueous solution," Chemistry -A European Journal, vol. 18, no. 28, pp. 8588-8590, 2012.

[19] D. W. van Krevelen, Properties of Polymers, Elsevier, Amsterdam, The Netherlands, 3rd edition, 1990.

[20] D. Zhang, M. A. Hillmyer, and W. B. Tolman, "A new synthetic route to poly[3-hydroxypropionic acid] ( $\mathrm{P}[3-\mathrm{HP}])$ : ringopening polymerization of 3-HP macrocyclic esters," Macromolecules, vol. 37, no. 22, pp. 8198-8200, 2004.

[21] J. H. Gross, Mass Spectrometry, Springer, Heidelberg, Germany, 2004. 

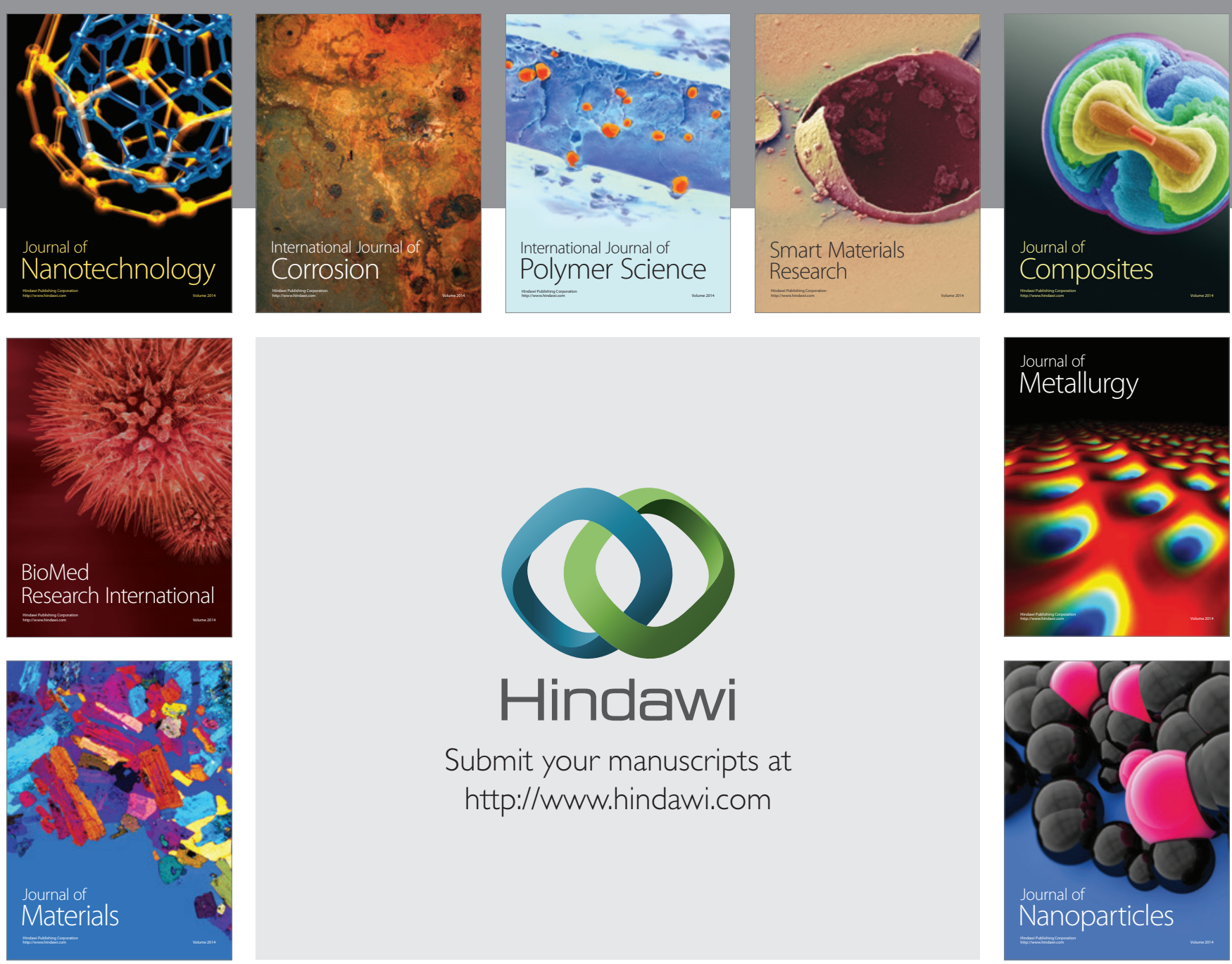

Submit your manuscripts at http://www.hindawi.com
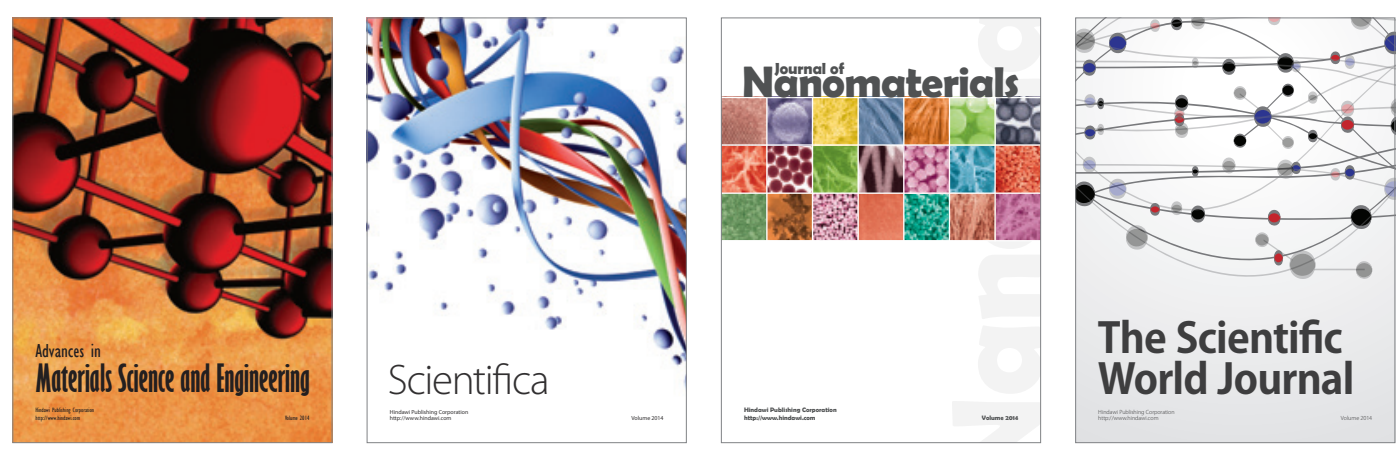

\section{The Scientific World Journal}
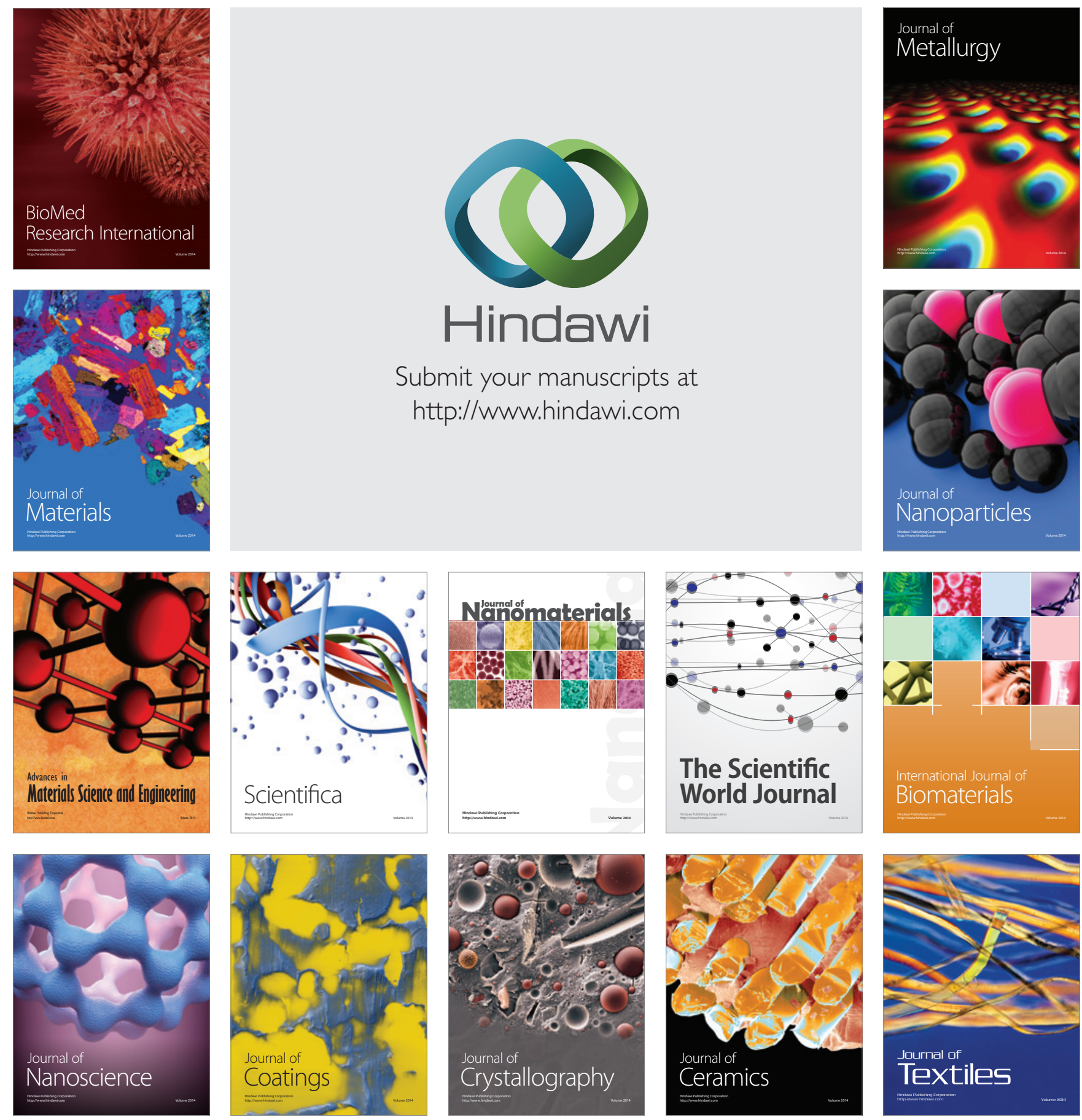